\title{
Inhalt
}

\section{Abbildungsverzeichnis - VII}

Tabellenverzeichnis — IX

$1 \quad$ Einführung -1

2 Zur Philosophie des Glücks - 3

$2.1 \quad$ Was ist Glück? - 3

2.2 Glückskonzepte in der zeitgeschichtlichen Entwicklung - 5

2.3 Die Balance von „Grow“ und „Flow“—11

3 Glücksforschung - eine empirische Wissenschaft? - 16

3.1 Ist Glück messbar? - 16

3.2 Messinstrumente $-\mathbf{3 0}$

$4 \quad$ Biologische Voraussetzungen von Glück - 38

4.1 Wie entsteht Glücksempfinden? - 38

4.2 Gibt es ein Glücks-Gen? - 41

$5 \quad$ Glück und Persönlichkeit - 48

5.1 Der Einfluss von Persönlichkeit auf Glück — 48

5.2 Die Wirkung von Glück auf Persönlichkeit — 50

5.3 Die Wirkungsrichtung $\mathbf{5 2}$

$6 \quad$ Glück in der Gesellschaft $-\mathbf{5 5}$

6.1 Glück im persönlichen Lebensverlauf - $\mathbf{5 5}$

6.2 Megatrends und Glück — 66

$6.3 \quad$ Kultur und Glück — 81

6.4 Schönheit und Glück -88

$7 \quad$ Glück durch soziale Beziehungen - 92

7.1 Soziale Beziehungen - 92

7.2 Beglückende Kontakte - 95

7.3 Soziale Vergleichsprozesse - 107

8 Die Glücksgesellschaft: Staat, Glück und Gesellschaftsordnung - 116

8.1 Wohlstand, Wachstum, Wohlbefinden — 116

8.2 Wohlfahrtsmaße - 130

8.3 Macht Bildung unglücklich? 135

8.4 Staatssystem und Rahmenbedingungen - 138 
9 Glück und Arbeit - 146

9.1 Arbeitszufriedenheit in Deutschland - 146

9.2 Die Bedeutung der Arbeit — 147

9.3 (Un-)Glücksfaktoren von Arbeit - 156

10 Implikationen - 167

$10.1 \quad$ Makroebene - 167

10.2 Mesoebene - 172

$10.3 \quad$ Mikroebene $-\mathbf{1 8 0}$

Literatur -193 